provide a welcome stimulus to standards of comfort and catering.

I welcome others' views on this subject.

Department of Geriatric Medicine,

Addenbrooke's Hospital,

Cambridge CB2 2QQ

\section{Uptake of cervical smear testing among travellers}

SIR, - The problems of increasing the uptake of cervical smear testing among Asian women ${ }^{1-3}$ help to put in perspective the problems of screening and preventive care in another subgroup of the population, travellers.

Among our practice population of 7200 we have some 400 travellers. Within our target group aged 25-65 we have 77 travelling women. How do we call them for screening? Their address is an illega campsite, they have no reliable postal service or telephones for follow up, and many within a family group have the same names. Opportunistic screening and personal visits to the site are the only alternatives.

Examination of medical records before our survey showed that only 11 of the women had ever had a cervical smear test. We are acutely aware of the difficulties of maintaining accurate medical records for travellers owing to their mobility and that our medical records may not contain details of cervical smear tests performed in other parts of Ireland and the United Kingdom.

The practice nurse visited the site to discuss cervical smear testing with women in the target group. She was informed that 57 of these had left the site. We are unsure of the accuracy of this as travellers are reticent about discussing gynaecological issues. Of the remainder, only 10 women were available for interview despite four visits to the site. Of these 10 women, all had had a cervical smear test within the past five years, nine within 18 months.

What do these results show? On one hand, they show the problems of identifying a denominator in any analysis of uptake of screening among travellers. On the other hand, they show a remarkable $100 \%$ uptake among the women interviewed. We conclude that the effectiveness of screening is indeed difficult to assess, especially among travellers.

DOMHNALL MACAULEY URSULA ANDERSON

Belfast B'T11 9FZ

1 McAvoy BR, Raza R. Can health education increase uptake of cervical smear testing among Asian women? BMF 1991;302: 833-6. (6 April.)

2 Carter JM, Ellerby SE. Increasing the uptake of cervical smear testing among Asian women. BMf 1991;302:1152. (11 May.) 3 Hoare T, Johnson C. Increasing the uptake of cervical smear testing among Asian women. BMf 1991;302:1540. (22 June.)

\section{Target payments for cervical smears}

SIR, - Contrary to Professor D C Morrell's general prediction,' in Kensington, Chelsea, and Westminster Family Health Services Authority uptake of cervical smears has increased considerably since the introduction of target payments (table). The increase is a result of more smears being taken by general practitioners (the number of smears going through local laboratories from general practitioners (April 1990 to January 1991) has increased by $33 \%$ (cytology department, St Mary's Hospital)) and improved administrative arrangements.

We are, however, concerned about the adverse incentives introduced by the target payments. In this area the turnover of patients exceeds $30 \%$ a year; many general practitioners still wish to achieve the $80 \%$ target. To protect the financial viability of their practice in a fast changing environment the payment system encourages them to be cautious and selective about who they accept on to their lists. The incentive is to give preference to patients who are likely to stay in the area for more than three years and who are prepared to have a smear test. The more mobile and arguably more needy - for example, homeless families - might be discriminated against.

We suggest, therefore, that the government should review the target payment for cervical cytology in inner city areas and reward practices achieving $50 \%$ uptake with the fee that practices in other areas receive for achieving the $80 \%$ target.

$S$ A HARGREAVES S JOHNSON

Kensington, Chelsea, and Westminster Family Health Services Authority, London SW6 4UL

1 Morrell DC. Role of research in development of organisation and structure of general practice. BM $1991 ; 302: 1313-6$. (1 June.)

\section{Confidentiality in case reports}

SIR,-The short report by Drs Magne Nylenna and Povl Riis' and the accompanying editorial by Ms Jane Smith ${ }^{2}$ on protecting patients' anonymity are obviously very well intended. We should not, however, lose sight of possible unwanted effects. Medicine makes progress because doctors learn from what happens to their patients and continue the age old habit of telling each other their patients' stories. Think about major side effects of drugs. A patient who is reported on in a medical journal because of a major side effect of a newly marketed drug is identifiable if only age and sex are given and the report is written by the patient's general practitioner. Given that both the prescription and the side effects are rare and the general practitioner has a list of only 2500 people, anyone who has malevolent intentions-say, an investigative journalist - could trace the patient just by going to the area of the practice, listening to gossip, and making a few telephone calls. Suppose that by some quirk of recalcitrance the patient refuses to have the side effect reported. Doesn't he or she thereby harm all future patients treated by the same drug?

We need to perform two balancing acts. The first is between the autonomy of patients and the progress of medical science. The second is between "malevolent" searching for a patient's identity versus normal human behaviour. A truly determined searcher will almost always be able to identify a patient. Most people who read case histories, however, do not have that intention. Should we really always be prepared for the worst, or does it suffice to protect the patient's confidentiality to a sufficient degree that the ordinary reader of the case report cannot immediately identify him or her?
As to the idea of omitting all "unnecessary" details, what are they? Certainly, we omit all details that seem to us of no value at this moment. Will later users of our case report uphold our judgment? Currently, I am doing a literature search in which the additional information about the patients is of great value. Finally, what about clinical pathological conferences, presented either in writing or orally? They are important educational tools and should continue, but they usually give a wealth of detail about the patient.

In the last century patients and their doctors were often identified completely in case reports. When photography entered medical journals it took some time before we recognised the need to omit faces or use black bars. As is clearly shown in Ms Smith's editorial, this works only for the average patient. Should we now become even stricter? Before we decide to do so we might wonder what values we are balancing.

$J$ P VANDENBROUCKE

Department of Clinical Epidemiology,

Leiden University Hospital,

PO Box 9600 ,

2300 RC Leiden,

The Netherland

1 Nylenna M, Riis P. Identification of patients in medical publications: need for informed consent. BMJ 1991;302:1182. (18 May.)

2 Smith J. Keeping confidences in published papers. $B M \mathcal{F}$ 1991;302:1168. (18 Mav.)

\section{Increases in BMA subscriptions}

SIR, - I wish to criticise the considerable increases in the BMA's subscription rates agreed at the recent annual representative meeting.' The way in which the recommendations for increases were stated was misleading. ${ }^{2}$ The increase in the standard rate is just over $14 \%$, and the increase in the retired ("pensioner") rate is just over $70 \%$. How can this be justified, especially considering that active practitioners may have a tax allowance on their subscriptions and retired members cannot?

Is it not time that the BMA stopped calculating how it can spend more money on staff and expanding services and stopped those meetings and services that are poorly attended or used?

CALUM N MCFARLANE

Walsall WS5 3HF

Increase in BMA subscription rates. BMF 1991;303:128-9.

2 BMA. Agenda of annual representative meeting 1991. London BMA, 1991:6.

**The secretary of the BMA replies: The council decided to make recommendations to the representative body for changes in members' subscription rates in the light of a detailed report on the association's income structure. This showed that the $49 \%$ of members who were paying the full rate were contributing $73 \%$ of subscription income. The council believed that the incomes of many of those paying reduced subscription rates were disproportionate to the substantial discounts they received. It regretted the need to recommend that the rate charged to retired members should be increased from $25 \%$ to $37 \cdot 5 \%$ of the standard rate, but this was part of a general restructuring of rates which it believes will be more equitable for all members.

\section{Correction}

\section{Freedom of speech in the new NHS}

In the footnote by the secretary of the BMA to the letter by Dr T Low-Beer and others (6 July, p 53) the second sentence should have referred to paragraph 330 (not paragraph 190) of the terms and conditions of service of consultants. We apologise for this error.

\begin{tabular}{lcccc}
\hline & April 1990 & July 1990 & October 1990 & January 1991 \\
\hline No of eligible women & 114365 & 114974 & 118471 & 112522 \\
No(\%) smear tested & $33214(29)$ & $40140(35)$ & $43109(36)$ & $45727(41)$ \\
No(\%) smear tested by general practitioner & $22423(68)$ & $19587(49)$ & $23692(55)$ & $25461(56)$ \\
\hline
\end{tabular}

